\title{
Management of Dental Waste in Private Clinics in Chhattisgarh State, India - A Cross Sectional Study
}

\author{
Dr. Ruchi Arora ${ }^{1}$, Dr. Ankush Agrawal ${ }^{2}$, Dr. Deepesh Singh $^{3}$, \\ Dr. Jyothirmai Reddy ${ }^{4}$ \\ ${ }^{I}$ (Department of Pedodontics and Preventive Dentistry / RUHS. INDIA) \\ ${ }^{2}$ (Department of Pedodontics and Preventive Dentistry / RUHS. INDIA) \\ ${ }^{3}$ (Department of Pedodontics and Preventive Dentistry / RUHS. INDIA) \\ ${ }^{4}$ (Department of Public Health Dentistry / RUHS. INDIA)
}

\begin{abstract}
Aims: Dentistry is a profession dedicated to promoting and enhancing oral health and well-being. To accomplish these goals, dentists use a variety of materials and equipment. Unfortunately, some of the materials that are currently in use like silver amalgam, x-ray films etc. including heavy metals and biomedical waste present potential challenges to the environment. Hence the aim of the present study was to assess the management of dental waste in private clinics of Chhattisgarh state, India. Methods and Material: A selfadministered questionnaire was designed and distributed among 100 practising dentists, who were private practitioners. The survey form was composed of 27 questions framed based on knowledge, attitude and those regarding the practice of dentists in relation to dental health-care waste management. Chi-square test (with Yates correction; wherever applicable) was used for analysing the factors influencing waste management practices. Results: Programs about waste management practices had significant influence on the knowledge of respondents about waste management guidelines $(P$ value $=0.01)$, on application of colour coding practice for disposal of waste $(P$ value $=0.01)$ and on disposal of amalgam $(P$ value $=0.01)$. The knowledge about waste management guidelines has significant influence on application of colour coding practice for disposal of waste $(P$ value < 0.0001).Conclusions: Though most dentists were aware of the hazardous effect of improper disposal of dental waste; majority of them still practiced improper waste disposal. There is need to retrain the practitioners on the importance and new technologies of proper waste disposal.
\end{abstract}

Key-words: Dental solid waste, solid waste management, dental clinics.

\section{Introduction}

Hospitals are health institutions providing patient care services. It is the duty of hospitals and health care establishments to look after the public health. This may directly be through patient care or indirectly by ensuring a clean, healthy environment for their employees and the community. In the process of health care, waste is generated which usually includes sharps, human tissues or body parts and other infectious materials, also referred to as "Hospital Solid Waste" and "Bio-medical Solid Waste" [1,2].

The Government of India (Notification, 1998) specifies that Hospital Waste Management is part of hospital hygiene and maintenance activities. This involves management of a range of activities, which are mainly engineering functions, such as collection, transportation, operation/treatment of processing systems and disposal of waste. However, initial segregation and storage activities are the direct responsibility of nursing personnel who are engaged in the hospital [3].

The term 'clinical waste' is associated with waste originating from medical, dental and veterinary sources and has been defined as 'waste that is contaminated with blood, saliva or any other bodily hazardous fluids and which may prove hazardous to any person coming into contact with it' (Department of Health, 1992). The World Health Organisation (WHO) has defined healthcare waste as 'all waste produced by healthcare establishments, research facilities and laboratories including the waste originating from 'minor' or 'scattered' sources such as that produced in the course of healthcare undertaken in the home (such as dialysis and insulin injections)' (WHO, 1999) [4].

The term biomedical waste has been defined as "any waste that is generated during the diagnosis, treatment, or immunization of human beings or animals, or in the research activities pertaining to or in the production or testing of biological and includes categories mentioned in schedule I of the Biomedical Waste (Management and Handling) rules 1998" [5,6].

Health care establishments (including dental clinics) are mainly concerned with providing high standard services to the community; this cannot be fully accomplished unless a proper waste handling policy that is consistent with the international regulations is strictly implemented. Even though dental clinics generate relatively small quantities of healthcare waste compared to the other medical facilities. Nevertheless they are 
responsible for generating a certain amount of waste which can produce serious health and environmental hazards if not dealt with properly [7].

Dentistry is a profession dedicated to promoting and enhancing oral health and well-being. To accomplish these goals, dentists use a variety of materials and equipment. Unfortunately, some of the materials that are currently in use - including heavy metals and biomedical waste - present potential challenges to the environment [8].

The common sources of major hazardous waste at dental clinics includes X-ray fixers and film, chemical disinfectants, dental amalgam, sharps and blood-soaked dressings, silver, lead, various solvent and other chemicals [9].

The key to minimization and effective management of health care waste is segregation (separation) and identification of the waste. Appropriate handling, treatment and disposal of waste by type reduce costs and do much to protect public health [10].

\section{Subjects And Methods}

A descriptive cross-sectional study was conducted among dentists from private sector of Chhattisgarh state. A convenient sample of dental practitioners was included in the study. A self-administered pretested questionnaire was used to record age, sex, type of practice, years of practice, additional training, knowledge attitude and practices on dental waste. The survey form was composed of 27 questions framed based on knowledge, attitude and those regarding the practice of dentists in relation to dental health-care waste management. Confidentiality of the participants was maintained by coding of the questionnaires. The percentage response for each question from all the participants was obtained and the data was subjected to statistical analysis (Chi-square test).

\section{Results}

A total of 100 questionnaires were distributed among private practitioners of Chhattisgarh state of which $84 \%$ were male and $16 \%$ were female. Most of the respondents were BDS (76\%) and 24\% were MDS. Among the respondents $54 \%$ were practicing since past 5 years, $28 \%$ were practicing since $6-10$ years, $14 \%$ were practicing since 11-15 years and only $4 \%$ were practicing since 16-20 years. Average OPDs of most of the clinics were between 1 and 10 per day (86\%) while $11 \%$ clinics were with 11-20 OPDs per day and only 3\% clinics were with 21-30 OPDs per day. [ Table 1]

$47 \%$ of the respondents indicated to have attended training on management of dental waste or had been attending continuous dental education. $48 \%$ practitioners were aware of waste management guidelines and same percentile said that they are using colour coded containers in their clinics. [Table 2]. Waste management practice among the respondents is described in detail in Table 3.

Attending training or CDE programme about waste management practices has significant influence on knowledge of respondents about waste management guidelines $(\mathrm{P}$ value $=0.01)$, on application of colour coding practice for disposal of waste $(\mathrm{P}$ value $=0.01)$ and on disposal of amalgam $(\mathrm{P}$ value $=0.01)$.

The knowledge about waste management guidelines has significant influence on application of colour coding practice for disposal of waste ( $\mathrm{P}$ value $<0.0001)$, on time interval of disposal of waste ( $\mathrm{P}$ value $=0.04$ ), on disposal of dental cements ( $\mathrm{P}$ value $=0.02)$, on disposal of sharps and needle $(\mathrm{P}$ value $=0.01)$, on disposal of discarded medicines $(\mathrm{P}$ value $=0.04)$, on disposal of protective wears $(\mathrm{P}$ value $=0.04)$ and on disposal of used suction tips $(\mathrm{P}$ value $=0.01)$.

Tables

Table 1: Demographic profile of the participating dentists

\begin{tabular}{|c|c|c|c|}
\hline \multicolumn{2}{|l|}{ Characteristics } & $\mathrm{n} \%$ & Total \\
\hline \multirow[t]{2}{*}{ Gender } & Male & $84(84 \%)$ & \multirow[t]{2}{*}{100} \\
\hline & Female & $16(16 \%)$ & \\
\hline \multirow[t]{2}{*}{ Designation } & BDS & $76(76 \%)$ & \multirow[t]{2}{*}{100} \\
\hline & MDS & $24(24 \%)$ & \\
\hline \multirow{4}{*}{ Practicing Since } & $0-5$ years & $54(54 \%)$ & \multirow{4}{*}{100} \\
\hline & $6-10$ years & $28(28 \%)$ & \\
\hline & $11-15$ years & $14(14 \%)$ & \\
\hline & $16-20$ years & $4(4 \%)$ & \\
\hline \multirow{4}{*}{$\begin{array}{l}\text { Average OPD (per } \\
\text { day) }\end{array}$} & $1-10$ & $86(86 \%)$ & \multirow{4}{*}{100} \\
\hline & $11-20$ & $11(11 \%)$ & \\
\hline & $21-30$ & $3(3 \%)$ & \\
\hline & $>30$ & $0(0 \%)$ & \\
\hline
\end{tabular}


Table 2: Dentists reported knowledge about waste management practices

\begin{tabular}{|l|c|c|c|}
\hline \multirow{2}{*}{ Characteristics } & \multicolumn{2}{|c|}{$\mathrm{n} \%$} & \multirow{2}{*}{ Total } \\
\cline { 2 - 3 } & Yes & No & \\
\hline Attended training or CDE programme & $47(47 \%)$ & $53(53 \%)$ & 100 \\
\hline Awareness about waste management guidelines & $48(48 \%)$ & $52(52 \%)$ & 100 \\
\hline Using colour coded containers & $48(48 \%)$ & $52(52 \%)$ & 100 \\
\hline
\end{tabular}

Table 3: Waste management practice among the respondents

\begin{tabular}{|c|c|c|c|}
\hline \multicolumn{2}{|c|}{ Characteristics } & \multirow{2}{*}{$\begin{array}{r}\mathrm{n} \% \\
79(79 \%)\end{array}$} & Total \\
\hline \multirow[t]{3}{*}{ Amalgam } & General Waste & & \multirow[t]{3}{*}{100} \\
\hline & Improper manner & $13(13 \%)$ & \\
\hline & Recommended manner & $8(8 \%)$ & \\
\hline \multirow[t]{3}{*}{ Dental Cements } & General Waste & $71(71 \%)$ & \multirow[t]{3}{*}{100} \\
\hline & Improper manner & $23(23 \%)$ & \\
\hline & Recommended manner & $6(6 \%)$ & \\
\hline \multirow[t]{3}{*}{ Sharps/Needle } & General Waste & $16(16 \%)$ & \multirow[t]{3}{*}{100} \\
\hline & Improper manner & $24(24 \%)$ & \\
\hline & Recommended manner & $60(60 \%)$ & \\
\hline \multirow[t]{3}{*}{ Files/Reamers/Burs } & General Waste & $78(78 \%)$ & \multirow[t]{3}{*}{100} \\
\hline & Improper manner & $11(11 \%)$ & \\
\hline & Recommended manner & $11(11 \%)$ & \\
\hline \multirow[t]{3}{*}{ Discarded Medicine } & General Waste & $87(87 \%)$ & \multirow[t]{3}{*}{100} \\
\hline & Improper manner & $9(9 \%)$ & \\
\hline & Recommended manner & $4(4 \%)$ & \\
\hline \multirow[t]{3}{*}{ Protective Wears } & General Waste & $22(22 \%)$ & \multirow[t]{3}{*}{100} \\
\hline & Improper manner & $39(39 \%)$ & \\
\hline & Recommended manner & $39(39 \%)$ & \\
\hline \multirow[t]{3}{*}{ Used X-Ray Films \& Solution } & General Waste & $26(26 \%)$ & \multirow[t]{3}{*}{100} \\
\hline & Improper manner & $65(65 \%)$ & \\
\hline & Recommended manner & $9(9 \%)$ & \\
\hline \multirow[t]{3}{*}{ Contaminated Gauze pieces/Cotton } & General Waste & $14(14 \%)$ & \multirow[t]{3}{*}{100} \\
\hline & Improper manner & $42(42 \%)$ & \\
\hline & Recommended manner & $44(44 \%)$ & \\
\hline \multirow[t]{3}{*}{ Anatomical Waste } & General Waste & $13(13 \%)$ & \multirow[t]{3}{*}{100} \\
\hline & Improper manner & $45(45 \%)$ & \\
\hline & Recommended manner & $42(42 \%)$ & \\
\hline \multirow[t]{3}{*}{ Used Suction Tips } & General Waste & $65(65 \%)$ & \multirow[t]{3}{*}{100} \\
\hline & Improper manner & $23(23 \%)$ & \\
\hline & Recommended manner & $12(12 \%)$ & \\
\hline
\end{tabular}

\section{Discussion}

The questionnaire study was chosen as it allows us to collect lot of information and data from a large number of respondents relatively quickly. The participants were chosen randomly from the urban and rural areas of Chhattisgarh state, India. Safe handling of hazardous waste is essential. All involved personal need to be aware of possible health hazards present and must be trained in the appropriate handling, storage and disposal methods. It was disappointing to find that the majority of the dentists did not have any knowledge of any documents outlining waste management, which does not only jeopardize the safety of the workers, but also causes avoidable mishaps in handling of dental waste. Sharps such as needles, syringes and used ampules are regarded as highly hazardous health care waste since they can cause injuries and transmitted diseases, especially to waste collection, treatment and disposal personnel [7].

According to WHO, hospital waste produces $80-85 \%$ of non-hazardous waste and $15-20 \%$ of hazardous waste. The hazardous waste can be infectious (10\%) like sharps or noninfectious (5\%) such as chemical and pharmaceutical waste. Collection of biomedical waste should be done as per BMW (management 
and handling rules, 1998) rule 6, Schedule II and the containers/bags should be labeled as per guidelines of schedule III, i.e, biohazard and cytotoxic symbol $[6,11,12]$.

Another important issue is the types of plastic bags used for collection of waste. The plastic bags used for waste disposal are special non-chlorinated, which can be incinerated. Normal plastic bags if used, will release dioxins and furans which further pollute the environment.

According to BMW (management and handling rules, 1998, Schedule I) [6]

- All the items sent to incinerator/burial, should be placed in yellow colour bags, e.g., human anatomical waste, microbiological waste, and soiled plastic waste;

- All the biomedical waste to be sent for microwave/autoclave/chemical treatment should be placed in red coloured bags, e.g., infected plastic syringes, tubings, gloves, rubber dam sheets;

- Any waste which is sent to shredder after autoclaving/microwaving/chemical treatment is to be placed in blue/white translucent bags/containers, e.g., sharp containers for needles and used files.

In the present study it was found that more than half of respondents were not aware of waste management guidelines. Same results were found in study done in Nairobi, Kenya [4]. This could be due to lack of initiative by dental practitioners on acquiring new knowledge after training or lack of proper training at institution.

It was also found that $48 \%$ of the respondents indicated that it was important to follow set guidelines on management of dental waste while in the study done in Nairobi, Kenya $63.5 \%$ follow the set guidelines [4]. In the study done in Ajman, United Arab Emirates it was found that majority of the dentists did not have any knowledge of waste management guidelines [7].

While $60 \%$ of the dentists did apply the recommended manner for disposal of sharps/needle; only $11 \%$ of the dentists disposed files/reamers as sharp/needle. In the study done in Kenya $61 \%$ of respondents applied the recommended manner for sharps/needle [13]. Only $56 \%$ of the dentists knew the recommended manner for disposal of sharps/needle in the study done in Ajman, United Arab Emirates [7].

Needle stick and puncture wound injuries and resulting infections have been recorded in situations where sharps have been improperly handled and/or disposed. The sharps (needles, scalpel blades) are that category of waste that needs maximum precaution and care.

Only $8 \%$ dentists reported disposing the amalgam in a closed container, in previous studies it was stated that the contact and noncontact amalgam should be stored separately in different containers, the container should be labeled with biohazard symbol as recommended by American dental association guidelines should be followed for proper disposal of amalgam waste $[13,14,15]$.

Fourty Four percent of the dentists indicated that bloody/body wastes should be disposed according to set guidelines; while 56\% disposed bloody/body waste as general waste. In the study done in Nairobi, Kenya $56.1 \%$ respondents dispose the bloody/body waste according to the set guidelines [4]. Bloody/body waste are suspected of causing infection and set guidelines should be followed strictly for this type of waste.

\section{References}

[1]. Baveja G, Muralidharar S, Aggarwal P. Hospital Waste Management - an overview. Hospital Today 2000; 5(9):485-6.

[2]. Manohar D, Reddy P R, Kotaih B. Characterization of solid waste of a super speciality hospital - a case study. Ind J Environ Health 1998;40(4):319-26.

[3]. Info Nugget, Hospital Waste Management and Bio-Degradable Waste. Government of India, Press Information Bureau, http://pib.nic.in/infonug/infaug.99/i3008991.html - downloaded on 18.10.2012.

[4]. Osamong LA, Gathece LW, Kisumbi BK, Mutave RJ. Management of Dental Waste by Practitioners in Nairobi, Kenya. Afr J Oral Health 2005;2(1\&2):24-9.

[5]. Govt. of India, "Bio-medical waste (management and handling) rules". The gazette of India. Ministry of Environment and Forest. 1998.

[6]. National guidelines on Hospital waste management. Biomedical waste regulations. 1998.

[7]. Hashim R, Mahrouq R, Hadi N. Evaluation of Dental Waste Management in the Emirate of Ajman, United Arab Emirates. Journal of International Dental and Medical Research 2011;4(2):64-9.

[8]. Hiltz M. The Environmental Impact of Dentistry. J Can Dent Assoc 2007;73(1):59-62.

[9]. Central of Disease Control, Hepatitis B fact sheet, July, 2007. http://www.cdc.gov/NCIDOD/Diseases/Hepatitis/b/bfact.pdf, (accessed 18.10.2012)

[10]. National Center for Chronic Disease Prevention and Health Promotion. Guidelines for Infection Control in dental Health-Care Settings, CDC, USA, 2003.

[11]. Manual for control of hospital associated infections. Standard operative procedures. National AIDS control organization; 1999. p. $1-34$.

[12]. Block 2 Health care Waste: Definitions; BHM-001 Fundamentals: Environment and Health, Health Care Waste Management regulations. School of Health Sciences, Indira Gandhi National Open University.

[13]. Best Management Practices for Amalgam Waste. American Dental Association, Oct 2007.

[14]. Dental Mercury Hygiene Recommendations. J Am Dent Assoc 1999;130:1121-3.

[15]. Dental Mercury Hygiene Recommendations. J Am Dent Assoc 2003;134:1498-9. 